\title{
ELECTRIZARTE: USING ARTS TO IMPROVE ENGINEERING EDUCATION
}

\author{
Lochi Yu and Fabián Abarca \\ Department of Electrical Engineering, University of Costa Rica \\ \{lochiyu,fabarca\}@eie.ucr.ac.cr
}

\begin{abstract}
ElectrizArte" (spanish words combined from "electrify" and "art") consists of an extracurricular activity where students design, implement and operate electronic projects in which they combine arts with engineering. The students develop both engineering and artistic components of the event. The objectives of ElectrizArte are: use engineering to magnify the perception of the arts and conversely, use arts to show the capabilities of engineering. Another motivation for the students: they usually suffered from misunderstandings of what they do at school, among family and friends. This certainly undermines their motivation can affect their academic performance. With ElectrizArte, they can show off their abilities and demonstrate what they are capable of, and along the way, spark interest in engineering among the general public. The projects were conceived, designed and developed by 30 undergraduate students during the Winter quarter in 2011, and included fields such as: photonics, computer vision, power electronics, and digital electronics. Students have their own motivation and had to learn in those topics by themselves. All projects were shown to the general public at a campus-wide event, and as a result, students had a realworld design experience, a hands-on project and new knowledge complementing their academic courses.

ElectrizArte proved to be an attractive way to engage students in extracurricular activities including engineering and art, for the benefit and satisfaction of the participants. This activity is now likely to become an annual tradition.
\end{abstract}

Keywords: Education, Engineering, Art, Extracurricular.

\section{INTRODUCTION}

In our project, "ElectrizArte", we try to improve students' learning with two complementary approaches: using arts as a "bait" to catch their interest and addressing learning via an extracurricular strategy.

This project was born as an initiative to combine our career with a more active, fun activity that could give students an integral learning experience. The proposal was also a possible solution to the question: are curricular activities fulfilling all the needs of the new engineer?

The urgency to go beyond a "chalk and talk" class and to privilege a competence-based education has been broadly discussed around the globe [1][2][3][4]. This work is a practical, engaging and effective way to move towards that purpose.

We address two main problems in the education of our students: the possible lack of motivation, and the absence of hands-on projects.

The answer to these problems was an extracurricular activity which pedagogical method is a project-based learning, combined, in this case, with artistic activities.

The results showed a positive reaction from students and authorities of the University that made possible a useful experience.

The article is organized as follows: Section 2 explains the two main issues that the project deals with: motivation and project-based learning. In Section 3 "ElectrizArte" is explained and further details of its realization are given, in terms of its three main components: the artistic part, the technical part and the extracurricular nature of the project. Section 4 analyzes the place that this project occupied in the students' education and its pedagogical characteristics, the role of professors and its likelihood to be reproduced. Finally, Section 5 summarizes the most important conclusions.

\section{WHAT IS AT STAKE?}

\subsection{Matching interests and abilities}

Everyone has interests and abilities. Usually abilities are acquired in pursue of an interest, although it is not always the case. During high school, students are asked to choose something they like to do as a living, considering their interests and aptitudes. High school counselors usually focus in the students' academic strengths and the needs of society, sometimes completely disregarding their personal interests. Figure 1 shows possible combinations of interests, abilities and needs of society. 


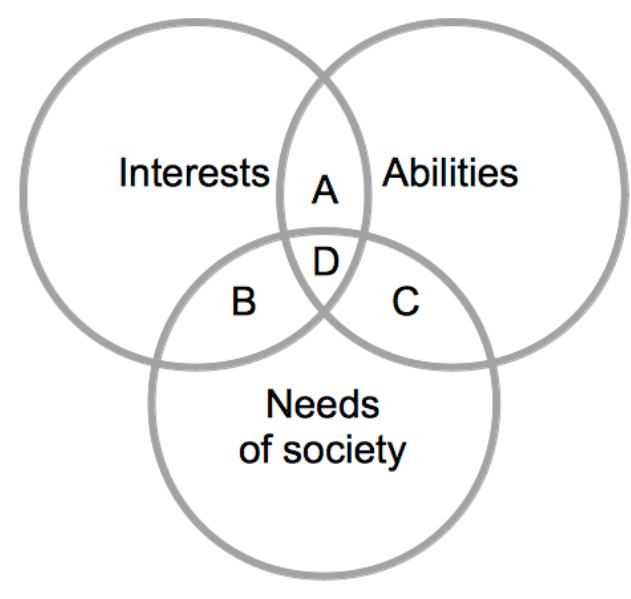

Fig. 1. Interests and abilities.

Sometimes students choose a major where they possess potential (e.g. mathematical ability) but are not very interested (point $\mathrm{C}$ ), or choose a major that they really like, but have not yet developed a specific ability (point B). Unfortunately for some, not all intersections yield a profession, as in point $\mathrm{A}$. The ones that are in point $\mathrm{D}$ are the ones that have chosen wisely. Students in point $\mathrm{B}$ and $\mathrm{C}$ deserve our main attention, because they are lacking full ease towards the career. These two kinds of students are easily identified: they are the ones that seem bored because everything is too easy or pose no challenge for them $(\mathrm{C})$, or the ones that pay attention, ask questions, and are generally interested but do fairly bad in evaluations (B).

The right combination of the students' career with their interests could yield a better development and awareness of their potential.

\subsection{Art and motivation}

Motivation is a key factor for students while they pursue a degree. Motivation is a key factor in the students' own learning process and a driving force in their life and career. There are a myriad of reasons why a student can or cannot be motivated to keep their career going with more than only "inertia" pushing forward.

Motivation is then at the core of the project. While paying attention to the underlying motivations (or lack of them), ElectrizArte represents a possibility for students to combine aspects of their life that were usually disconnected, such as engineering and art. It is attractive even for those students who are not likely to neither play an instrument nor perform any kind of "art." On top of this, many common problems of engineering will appear during the making of the individual projects, and that is the learning-by-doing scheme.

Most of us appreciate art, even though not all of us are artists. If we incorporate this interest back to our major, as a vehicle for learning, we can bring back the interest and motivation in order to develop the technical skills that are needed.

This argumentation leads to two main reciprocal goals in ElectrizArte:

- To use engineering to highlight the perception of art.

- To use art as a way to demonstrate what engineering can do.

\section{ELECTRIZARTE}

\subsection{The project: what is ElectrizArte?}

ElectrizArte is a place for art. It is where artistic performances can be presented by students themselves in a show. It is an opportunity to share abilities that are not commonly explored in college. But, equally important, ElectrizArte is a platform to develop engineering projects, most of them including light, sound, motion or whatever other artifacts that could be used to represent an artistic idea.

The name "ElectrizArte" is the combination, in Spanish, of "electricity" and "art", meaning "to electrify you".

\subsection{Extracurricular activities: a new place to learn engineering}

One main characteristic of ElectrizArte is that it is an extracurricular activity.

In order to improve engineering education, there are efforts to transform the curricula and to implement a new skills-based vision of careers [3][4]. These are desirable long-term processes, which are, in fact, an imperative in an ever-changing environment, but they are all curricular activities. Instead, extracurricular activities have not been broadly addressed, and represent a different scenario with its own characteristics, opportunities and challenges.

Extracurricular activities are not intended to serve as an "extension" of the classroom; otherwise they would be denaturalized from their origin: a space to explore new and different fields, usually away from engineering. But what if the combination of engineering and arts transforms an extracurricular, non-related activity into an opportunity to learn while being amused? This question triggered the possibility of starting this project.

For students, participating in such project "out of the classroom" and "with no academic credit" implies willingness, and willingness almost surely implies motivation, furthermore, motivation implies a more open attitude towards learning and discovering. This, in turn, results in a better, integral and enriching experience for those who are involved.

\subsection{Projects}


When the goals are set, a question arises: what areas of engineering can be exploited? The answer was rather easy: all. We know there is something interesting to do in fields including but not limited to: analog electronics, digital electronics, computer vision and programming

It all started with the purpose of performing in an event. The event had two kinds of attractions: the artists themselves (engineering students) and the devices they designed and built. Every project would have one or more professors serving as technical advisers, but the students would be in charge of implementation, testing and/or stage performance. The design process started by discussing seminal ideas to develop, and then students were urged to figure out what would be the best way to get that idea done, using known topics of their major or new ones that they had to learn.

It was not a prerequisite to have the needed technical skills. In fact, one of the motivations that drove the students to choose a particular project was to acquire those specific skills (programming, analog design, digital design, etc.). One of the reasons we created ElectrizArte was to create a situation where each student would need (and want) to learn a particular skill or acquire a particular knowledge, outside a formal course. In this scenario, the student wants to learn in order to successfully implement their project, in contrast to being enrolled in a course where the motivation is to pass the course. Surely, as it happened, failing is part of the game but it does not end up without new learning.

Several projects were implemented and we detail some of them below.

3.3.1. Lumint. This musical interface evolved from the photonic harp, where the artist touches laser beams to produce a musical tone. Lumint is the retronym for "Laser of the University for Musical INTerface". Two students implemented this project using a regular webcam, a laptop, MIDI keyboard, and green lasers. The project included both software and hardware component. The software part was the biggest component, where they implemented computer vision algorithms to detect the light reflected by the artist's hand when it was struck by the laser beam. This software was implemented in $\mathrm{C}++$ using the OpenCV libraries, and was successfully published as our department's first open source project. This project drove the students to learn programming (they had no experience prior this), optics and analog electronics. The interaction and discussion with the performer derived on a tailoring of the software to bring on a better musical instrument and effect.

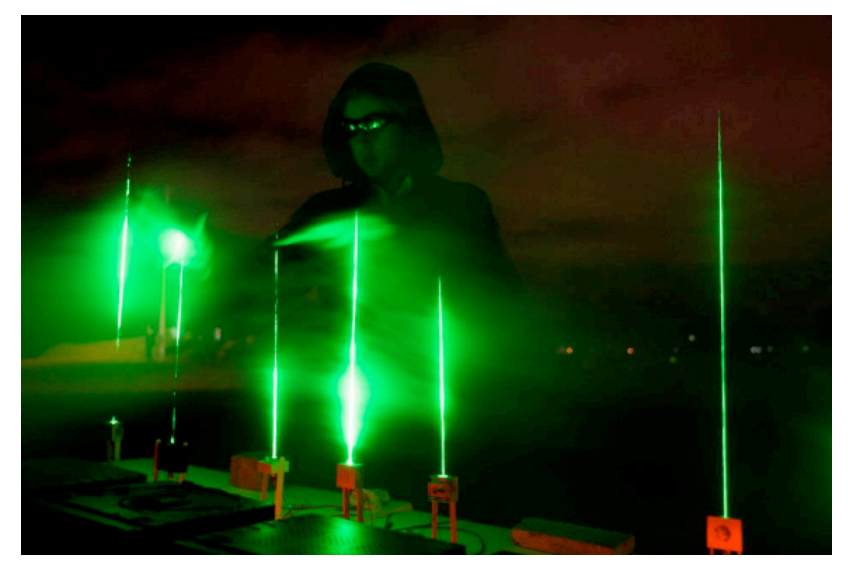

Fig. 2. A student performing an early version of the Lumint.

3.3.2. Tesla coil. The development of the Tesla coil required students to deepen their knowledge of the coil's characteristic electromagnetic resonant phenomena and to learn the implementation details and how to deal with a greater electric power. This illustrates the difference between a purely theoretical course and a hands-on project that demands some different but equally necessary skills when designing and implementing. The students involved in the making of this apparatus gained experience in working with high-power circuits, high frequency and electromagnetic devices.

3.3.3. LED cube. It is a three-dimensional array of several LED that light in such a sequence that create the illusion of $3 \mathrm{D}$ figures. This device is widely known among hobbyists and is, in fact, a YouTube success, where many have shown their own version of the LED cube. This project involved skills in programming and also extensive soldering. This had to be done by students who had no previous experience and perhaps little knowledge on these areas, so they had to learn, as in other projects, "on the fly," and implied a lot of dedicated work and learning. It was developed using the open hardware platform Arduino, which, incidentally, turned out to be one of the most used devices for these projects.

\subsection{University's Open House 2011 event}

What started as a concept that pretended to be a little show for our own delight, ended up as a full blown event that some 2000 persons attended. Around 60 students worked on their free time, for two months and all projects were shown to the general audience in March 2011, as part of a university "open house" event.

The students performed and demonstrated their projects successfully and had the chance to work along with students of careers as diverse as drama, sociology, 
other engineerings, etc. Figure 3 shows a snapshot of the performance.

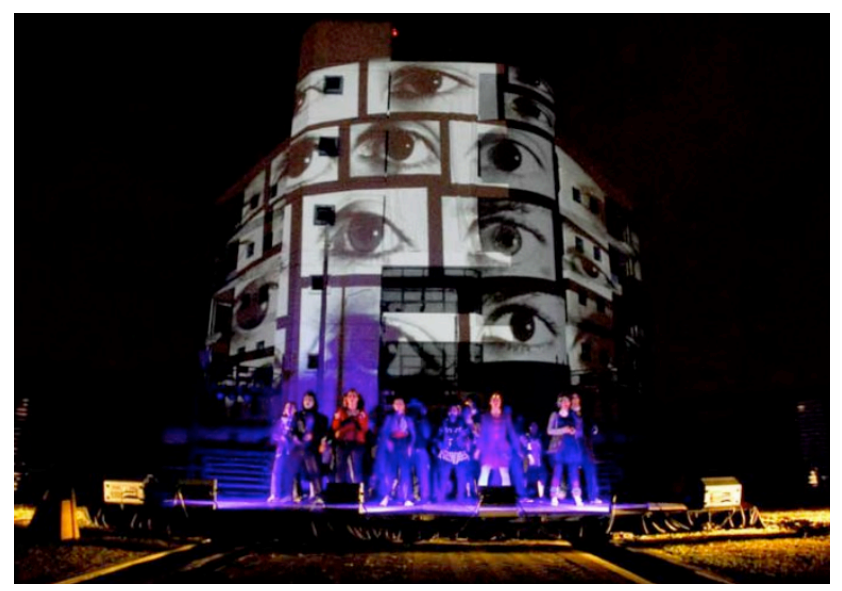

Fig. 3. Opening ceremony of the University's Open House event, in March 2011.

\section{ELEMENTS FOR ANALYSIS}

\subsection{Boosting initiative and imagination}

One differentiating factor of this project is the way students can freely make up their own ideas and struggle to accomplish them.

Art and engineering share a fundamental characteristic: they give people the freedom to imagine and create. This freedom is subject to some restrictions, of course, say physical or technical. These restraints are not limitations for creativity; but instead, they are triggers to innovate and figure out new ways to solve a given situation, thus demanding more creativity.

"The artistic problem" deals with the aesthetic representation of an idea. "The engineering problem" might be described in a similar way: it deals with the realization of an idea.

Then, what are the problems to be solved by engineers? Most of them are determined by society and its needs. But for this case, students are in charge of figuring out what they want to solve, both as an artistic and technical problem. In such situation, they needed initiative.

Scott Adam's cartoon character Dilbert stated: "Engineers like to solve problems. If they do not have problems handily available, they will make their own." Students, in this case "made their own problems." In such situation, they needed imagination.

Boosting initiative and imagination was useful to make a change of paradigm: one in which students are not just mere depositories of knowledge but instead they demand what they want to learn in the context of a problem they need (and want) to solve.

\subsection{The complement to formal education}

This project comes to fulfill some "gaps" (whether real or perceived) in the formal education of the career. These "holes" are listed as:

- A gap between theory and practice, which does not allow students to learn inherent and particular aspects of the subject that might only become evident when experiments take place.

- A gap between courses and areas of electrical engineering, meaning that they might look as isolated islands with no clear ties and joint applications.

- A gap between different engineering careers and,

- A gap between engineering and other disciplines (e.g. basic, social, economic sciences, etc.)

Although this is not an exhaustive list of problems in formal education in engineering, these problems could be effectively addressed in ElectrizArte, as we observed and as students told us.

\subsection{Project-based learning}

Beyond theory in the classroom, there are further steps that will help students accomplish better understanding of engineering, its capabilities, its role in society and the opportunities it offers. These steps are the design and the implementation.

Design and implementation are keywords of this project. It represents an opportunity for students to gather their knowledge together and bond it to a solution for a problem they need to solve.

As projects of design, they encompass the whole process, from planning to execution. A seminal idea comes from multiple sources, including existing devices, a mix of them or a wholly new concept. In all cases, the group in charge of design would reshape and mature the original idea, leading to a "best effort" approach to the solution.

ElectrizArte proved to contain all desirable components that build up an entire learning experience in electronics: learn the theory, draw the schematics, build the prototype, test it, redesign it and deploy it.

\subsection{Interdisciplinary work, group work and leadership skills}

A project, nowadays, is rarely confined to the boundaries of a sole area of knowledge. Engineering is not the exception. In this project, the need for multiple disciplines to converge in the solution of a problem has aroused naturally.

Also, as in any human organizations, a natural hierarchy appears during the making of the technological or artistic projects, where leaders take place. 
An opportunity for students to learn the abilities of interdisciplinary work, group work and leadership is desirable and valuable. ElectrizArte has proven to be a place for sharing and working together, instead of isolating individuals.

\subsection{The role of professors}

In principle, this is not a structured, guided process. Or, at least, it is not in its details. Many of the preferred courses of action will be determined "on the fly" and depending upon many circumstances. This is a project where students have the freedom to do whatever they want, or whatever they think is in the right path for a successful accomplishment of their goals. But here, precisely, is where the help of professors becomes valuable and desirable.

Projects are in fact very self-leading. They evolve according to some pre-established goals. If there is an unguided work, we may wonder whether the learning process of students will be productive and constructive, but students themselves expressed a favorable position about what they could learn by working and pushing forward by themselves.

Even though, some individual projects failed, but that does not mean necessarily that the process was disappointing or useless.

The project is still maturing, and there have been, of course, drawbacks. For example, there will be also a fight against the apathy of some, but one advantage is that as this is an extracurricular activity, unmotivated individuals will be most of times self-excluded.

\section{CONCLUSIONS}

ElectrizArte aims to continue with new students participating every year. After two years of activity, we have reached the following conclusions:

- Students, if well motivated, are willing to invest their free time to work and learn to design and implement complex hardware-software projects. In other words, motivation can "blur" the boundaries between curricular and extracurricular work.

- Art related projects motivate students, and create a completely different approach in their learning experience: they take their education in their own hands.

- The event helped students to develop skills such as: problem solving, leadership, interdisciplinary work, social abilities, and ability to apply knowledge in practice, among others. This is very important in the context of a transformation to a competence-based education, as stated by many, including [4].

- Similar projects can be developed elsewhere with the support of authorities and the enthusiasm of students. Professors in charge will not decimate their time because the work is done mainly by students themselves.

\section{References}

[1 Julie E. Mills and David F. Treagust, "Engineering Education - Is Problem-Based of Project-Based Learning the Answer?" Australasian Journal of Engineering Education, 2003.

Available as of May 3, 2013 from

http://www.aaee.com.au/journal/2003/mills_treagust03.pdf

[2] Lawrence E. Carlson and Jacquelyn F. Sullivan, "Hands-on Engineering: Learning by Doing in the Integrated Teaching and Learning Program," Int. J. Engng Ed., vol. 15, no. 1, pp. 20-31, 1999.

[3] National Academy of Engineering, The Engineer of 2020: Visions of Engineering in the New Century. Washington, DC: The National Academies Press, 2004 (1st ed.), 101 pp. \{ISBN: 0-309-53065-2\}

[4] Pablo Beneitone et al, Reflections on and outlook for Higher Education in Latin America. Final Report - Tuning Latin America Project 2004-2007. Bilbao, Spain: Publicaciones de la Universidad de Deusto, 2007, 419 pp. \{ISBN: \} Available as of May 3, 2013 from http://tuning.unideusto.org/tuningal/index.php?option=com docman\&Itemid=191\&task=view_category\&catid=22\&ord 